Article

\title{
Gas Sensing with Nanoplasmonic Thin Films Composed of Nanoparticles (Au, Ag) Dispersed in a CuO Matrix
}

\author{
Manuela Proença *, Marco S. Rodrigues $\mathbb{D}^{\mathbb{D}}$, Joel Borges * $\mathbb{D}$ and Filipe Vaz \\ Centro de Física da Universidade do Minho, Campus de Gualtar, 4710-057 Braga, Portugal; \\ marcopsr@gmail.com (M.S.R.); fvaz@fisica.uminho.pt (F.V.) \\ * Correspondence: manuelaproenca12@gmail.com (M.P.); joelborges@fisica.uminho.pt (J.B.); \\ Tel.: +351-253-510-471 (J.B.)
}

Received: 6 May 2019; Accepted: 23 May 2019; Published: 25 May 2019

\begin{abstract}
Magnetron sputtered nanocomposite thin films composed of monometallic $\mathrm{Au}$ and $\mathrm{Ag}$, and bimetallic $\mathrm{Au}-\mathrm{Ag}$ nanoparticles, dispersed in a $\mathrm{CuO}$ matrix, were prepared, characterized, and tested, which aimed to find suitable nano-plasmonic platforms capable of detecting the presence of gas molecules. The Localized Surface Plasmon Resonance phenomenon, LSPR, induced by the morphological changes of the nanoparticles (size, shape, and distribution), and promoted by the thermal annealing of the films, was used to tailor the sensitivity to the gas molecules. Results showed that the monometallic films, $\mathrm{Au}: \mathrm{CuO}$ and Ag:CuO, present LSPR bands at $\sim 719$ and $\sim 393 \mathrm{~nm}$, respectively, while the bimetallic $\mathrm{Au}-\mathrm{Ag}: \mathrm{CuO}$ film has two LSPR bands, which suggests the presence of two noble metal phases. Through transmittance-LSPR measurements, the bimetallic films revealed to have the highest sensitivity to the refractive index changes, as well as high signal-to-noise ratios, respond consistently to the presence of a test gas.
\end{abstract}

Keywords: thin films; magnetron sputtering; microstructure; noble metal nanoparticles; $\mathrm{CuO}$ matrix; localized surface plasmon resonance; gas sensor

\section{Introduction}

Nanocomposite thin films, containing noble metal nanoparticles embedded in an oxide matrix, have been a subject of considerable interest for optical gas sensing due to their localized surface plasmon resonance (LSPR) properties [1,2]. Surface plasmons are coherent oscillations of free electrons excited by an electromagnetic field at the boundaries between a metal and a dielectric. They can propagate along the surface of the conductor, which are designated by surface plasmon polaritons, or be confined to metallic nanoparticles or nanostructures, in which case, are denominated as localized surface plasmons [3-5]. LSPR can give rise to strong absorption bands, the enhancement of the electromagnetic field near the nanoparticles, and the appearance of scattering to the far field [6-10]. Since its discovery, there have been significant advances in both theoretical and experimental investigations of surface plasmons, which led to the development of new modelling methods that contribute to the understanding of the morphology and to the calculation of the optical properties of nano-plasmonic systems $[8,11,12]$.

The two most well studied plasmonic metals are gold (Au) and silver (Ag). They exhibit LSPR bands within the visible spectrum due to the energy levels of $d-d$ transitions, being used in various applications involving color $[13,14]$ as well as in sensing due to their relatively high refractive index sensitivity $[15,16]$. Since Ag nanoparticles present the sharpest and strongest bands among all metals, they are associated to higher sensitivity factors than Au. However, Au nanoparticles are more frequently selected for sensing applications due to their lower toxicity, inert nature (less prone to oxidation), and 
stability $[17,18]$. On the other hand, Ag-Au bimetallic nanoparticles have attracted particular attention due to their corresponding monometallic counterparts, which may allow further improvements on their set of properties [19-21], especially the optical behavior [16,21,22]. In fact, they are relatively easy to prepare since both metals have a face-centred cubic structure and similar lattice constants. However, it is known that the synthesis method can result in alloyed bimetallic nanoparticles [23,24], core-shell [25], and even Janus systems [26]. These features are determined by the Au/Ag ratio in the bimetallic nanostructure, which leads to different optical properties. From the alloy formation of $\mathrm{Au}-\mathrm{Ag}$ bimetallic nanoparticles, only one LSPR band results between the peaks of the constituting monometallic nanoparticles, while a mixed system originates two plasmonic bands, as reported in different works [3,22,23,27].

Diverse noble metal compositions dispersed in a dielectric matrix and different microstructures and nanostructures might be developed, which originates different LSPR bands, since their curvature and position are strongly dependent on different factors such as the composition, size, shape, and distribution of the nanoparticles, which are also sensitive to changes of the refractive index of the surrounding dielectric medium where they are dispersed [1,3]. Hence, the basis of the plasmonic bio/chemical sensors is established by the dependence of the LSPR band on the surrounding refractive index $[2,16,28]$. One of the advantages of using LSPR phenomenon for optical gas sensors in contrast to Surface Plasmon Resonance (SPR) systems is the fact that the first ones have a much higher potential to be sensitive to the extremely low refractive index changes such as those induced by gas molecules $[2,29,30]$, since the plasmon decay length in LSPR is much lower than in SPR [31]. Furthermore, LSPR-based sensors are basically supported by nanoparticles that can be directly coupled to light, while the SPR-based sensors are dependent on prisms, optical fibers, or gratings to be coupled with light $[30,32,33]$.

For the LSPR gas detection by refractive index changes to be functional, the production of highly sensitive plasmonic thin films is required, but the development of a high-resolution spectroscopy system to measure extremely small LSPR peak shifts is a fact that has been hampering the research on this area [2,34]. Hence, in order to optimize the sensitivity of the films, previous studies of the LSPR sensing response have been made by using two liquids with a relatively large refractive index difference $[28,35,36]$, which allowed us to estimate the refractive index sensitivity (RIS) [37-39].

The present work proposes a reliable and effective possibility of sensitive thin films, suitable to be used as optical sensors. Such (nanocomposite) thin films are based on $\mathrm{Au}$ and/or Ag nanoparticles, dispersed in a semiconductor copper oxide $(\mathrm{CuO})$ matrix, $\mathrm{Au}: \mathrm{CuO}, \mathrm{Ag}: \mathrm{CuO}$, and $\mathrm{Au}-\mathrm{Ag}: \mathrm{CuO}$, deposited by reactive DC magnetron sputtering. The use of a pure copper target containing gold and/or silver pellets on its surface, avoids the use of a second cathode $[40,41]$, with evident economic advantages $[3,28]$. After the preparation of the thin films, a thermal annealing treatment was performed in order to promote the necessary nanostructural changes in the noble metal nanoparticles, and dielectric matrix, which enabled the manifestation of the LSPR behavior, and, consequently, turned the thin films sensitive to the gas molecules. The composition and morphology of the thin films were studied and correlated with the LSPR responses. LSPR sensing tests were performed through transmittance measurements in a custom-made optical vacuum system, which incorporates a gas flow cell. The sensitivity of the different films to the presence of $\mathrm{O}_{2}$ gas was also calculated and compared between them.

\section{Materials and Methods}

Thin films of $\mathrm{Au}: \mathrm{CuO}, \mathrm{Ag}: \mathrm{CuO}$, and $\mathrm{Au}-\mathrm{Ag}: \mathrm{CuO}$ manifesting LSPR behavior were produced by a two-step process, involving deposition of the thin films and posterior thermal treatment. For the depositions, two different types of substrates were used including Si (Boron doped, $\mathrm{p}$ type, $<100>$ orientation, $525 \mu \mathrm{m}$ thick) for chemical and (micro)structural characterization purposes and $\mathrm{SiO}_{2}$ (fused silica) for optical spectra measurements. Before the depositions and in order to clean and activate the surface of the substrates, plasma treatments were performed by a Low-Pressure Plasma Cleaner 
by Diener Electronic equipped with a $40 \mathrm{kHz}$ RF generator (Zepto Model, Ebhausen, Germany) [42], applying a power of $100 \mathrm{~W}$. The substrates were first cleaned with $\mathrm{O}_{2}$ plasma ( $80 \mathrm{~Pa}$, for $5 \mathrm{~min}$ ), and then activated with Ar plasma (80 Pa, for $15 \mathrm{~min})$.

The films were deposited by reactive (DC) magnetron sputtering during $60 \mathrm{~s}$ in order to produce films with thicknesses around $\sim 50 \mathrm{~nm}$. As illustrated in Figure 1a, the above-mentioned substrates were then placed in a grounded hexagonal holder, rotating at $16 \mathrm{rpm}$ and $7 \mathrm{~cm}$ far from the cathode. The latter is a rectangular copper target $\left(200 \times 100 \times 6 \mathrm{~mm}^{3}, 99.99 \%\right.$ purity), where gold and/or silver pellets (surface area of $960 \mathrm{~mm}^{2}$ and $0.5 \mathrm{~mm}$ thick) were placed symmetrically on its preferential erosion zone. The base pressure was below $5 \times 10^{-4} \mathrm{~Pa}$, while the target potential was limited to $500 \mathrm{~V}$, and the applied current was $3.25 \mathrm{~mA} / \mathrm{cm}^{2}$. The discharge was ignited in a gas atmosphere composed of $\operatorname{Ar}\left(3.5 \times 10^{-1} \mathrm{~Pa}\right)$ and $\mathrm{O}_{2}\left(2 \times 10^{-2} \mathrm{~Pa}\right)$. Then, in order to promote the nanoparticles' growth, the films were subjected to thermal treatments in-air, up to a maximum temperature of $700{ }^{\circ} \mathrm{C}$, according to what was previously studied and published by the group [1,28]. The heating ramp used was $5^{\circ} \mathrm{C} / \mathrm{min}$ and the isothermal period was $5 \mathrm{~h}$, which cooled down freely inside the furnace, before reaching room temperature.

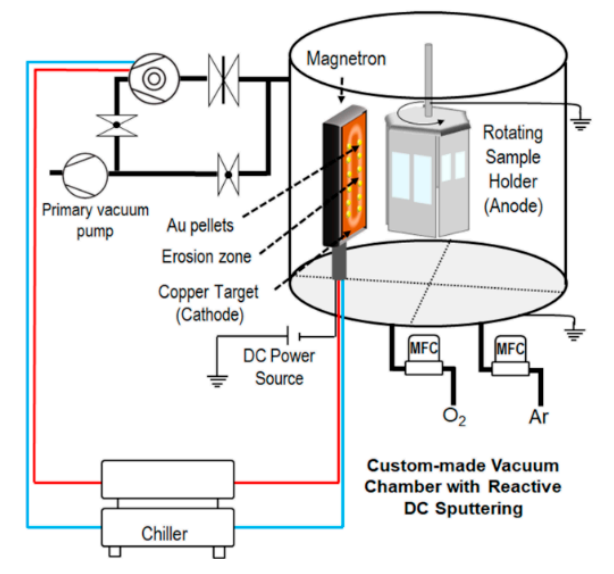

(a)

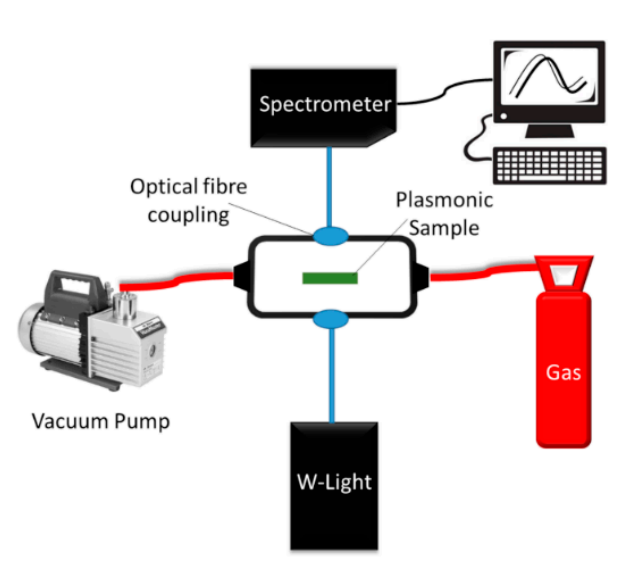

(b)

Figure 1. Simplified representation of the reactive DC magnetron sputtering system (a) and the custom-made system for transmittance-LSPR (T-LSPR) measurement in a controlled atmosphere (b).

The atomic composition of the films was studied by Rutherford Backscattering Spectrometry (RBS) using a Van de Graaff accelerator, a standard detector, placed at $140^{\circ}$, and two pin-diode detectors located symmetrically to each other, both placed at a $165^{\circ}$ scattering angle respective to the beam direction. Spectra were collected using $2.0 \mathrm{MeV} 4 \mathrm{He}^{+}$, and $1.45 \mathrm{MeV} 1 \mathrm{H}^{+}$beams at normal incidence and the data was analyzed with the IBA DataFurnace NDF v9.6i code [43].

The morphology of the films' surface was studied by a Dual Beam Scanning Electron Microscope, SEM/FIB FEI Helios 600i (Hillsboro, OR, USA), using a backscatter electron detector. The surface micrographs were analyzed using MATLAB software (version R2018a), by calculating the Feret diameter, the aspect ratio, and the nearest neighbor of the contrasted nanoparticles. The MATLAB algorithm included the locally adaptive threshold function "adaptthresh." After the binarization and scaling of the SEM images, the nanoparticles were analysed using the "regionprops" and "bwboundaries" functions.

The films' gas sensitivity was investigated by monitoring the LSPR band in the presence of $\mathrm{O}_{2}$ (atmospheric pressure), in comparison to a low vacuum pressure. Real-time measurements were performed in a custom-made system (Figure 1b), composed of two main parts: the optical components and a vacuum system. The optical system allows the measurement of the optical (transmittance) spectrum of the sample, using a tungsten lamp and a modular spectrometer by Ocean Optics (HR4000, Edinburgh, UK). Optical fibers were used to connect those components to the flow cell, where the sample is placed. A vacuum pump was used to produce a "primary" vacuum ( $40 \mathrm{~Pa})$ inside the flow 
cell and then $\mathrm{O}_{2}$ was introduced at atmospheric pressure for $120 \mathrm{~s}$. Several vacuum/ $\mathrm{O}_{2}$ cycles were employed and the LSPR peak position was monitored in real time. A MATLAB algorithm was written to smooth the spectra and find the position of the LSPR peak over time.

\section{Results}

\subsection{Thin Films Characterization}

The atomic concentration profiles of the thin films were determined by RBS (Figure 2). The as-deposited $\mathrm{CuO}$ matrix (solid lines), and the $\mathrm{CuO}$ matrix with thermal treatment at $700{ }^{\circ} \mathrm{C}$ (dash lines), are represented in Figure 2a, while the as-deposited nanocomposite films are displayed in Figure $2 b-d$. According to the RBS analysis, all the as-deposited thin films were found to have a roughly constant atomic concentration across their thickness, even after the annealing process for the case of the pure matrix. Moreover, elemental concentration results revealed that the matrix of the as-deposited films is not fully $\mathrm{CuO}$ stoichiometric, since the atomic ratio $C_{\mathrm{O}} / C_{\mathrm{Cu}}$ is always different from but close to 1 . However, as soon as the film is subjected to thermal annealing, it seems that the $\mathrm{CuO}$ matrix becomes stoichiometric, which can be observed by the corresponding RBS profile (Figure 2a), where $\mathrm{Cu}$ and $\mathrm{O}$ concentrations were estimated to be about $50.0 \pm 0.5$ at. $\%$ and $50 \pm 3$ at. $\%$, respectively. Thus, when the films are subjected to thermal treatment in air, the chemical composition may change in relation to the as-deposited films due to oxygen incorporation $[44,45]$, as previously verified $[1,28]$. The atomic concentration of noble metals into the $\mathrm{CuO}$ matrix was determined to be about $C_{\mathrm{Au}}=15.0 \pm 0.5 \mathrm{at} . \%$ $(\mathrm{Au}: \mathrm{CuO}), C_{\mathrm{Ag}}=17.7 \pm 0.5$ at. $\%(\mathrm{Ag}: \mathrm{CuO})$, and $C_{\mathrm{Au}}=6.7 \pm 0.5$ at.\%, $C_{\mathrm{Ag}}=8.0 \pm 0.5$ at. $\%(\mathrm{Au}-\mathrm{Ag}: \mathrm{CuO})$. These were the compositions of the thin films used for LSPR sensitivity tests.

(a)

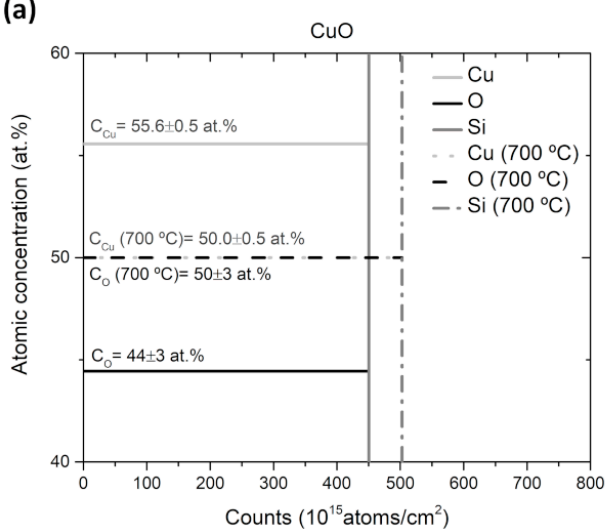

(c)

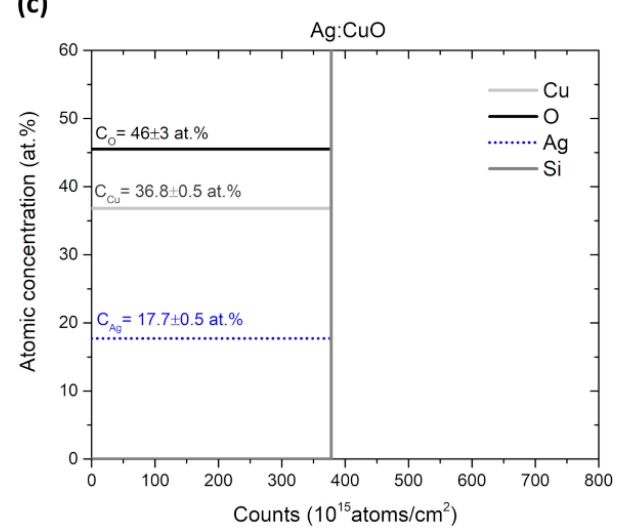

(b)

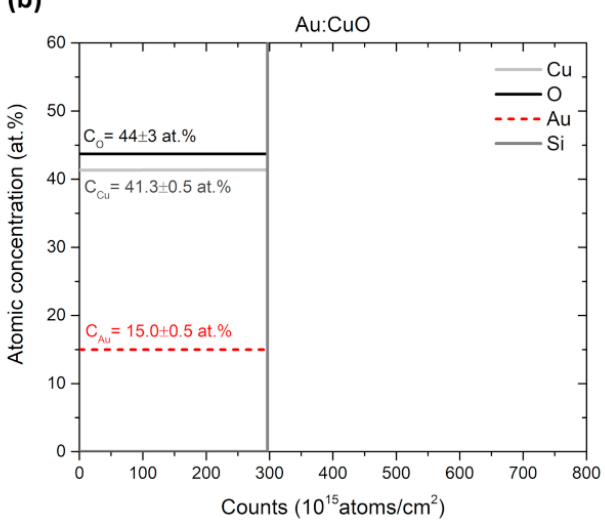

(d)

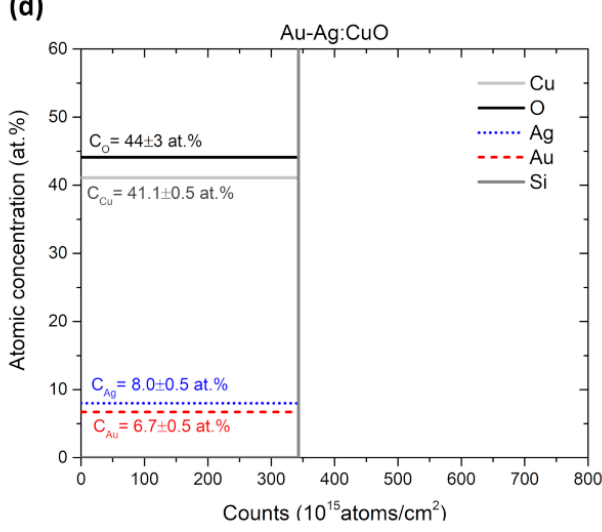

Figure 2. Atomic concentration (at.\%) of the different elements present in the as-deposited $\mathrm{CuO}$ matrix (solid lines (a)), in the $\mathrm{CuO}$ matrix with annealing at $700{ }^{\circ} \mathrm{C}$ (dash lines (a)), and in the as-deposited samples of $\mathrm{Au}: \mathrm{CuO}(\mathbf{b}), \mathrm{Ag}: \mathrm{CuO}(\mathbf{c})$, and $\mathrm{Au}-\mathrm{Ag}: \mathrm{CuO}(\mathbf{d})$ films deposited with a pellets' area of $960 \mathrm{~mm}^{2}$, obtained by the RBS data analyzed with the code IBA DataFurnace NDF v9.6i [43]. 
The $\mathrm{CuO}$ matrix annealed at $700{ }^{\circ} \mathrm{C}$ presents a polycrystalline structure with well-defined grain boundaries, as observed in the SEM micrograph displayed in Figure 3a. In addition, the optical transmittance spectrum (Figure $3 b$ ) reveals a semi-transparent $\mathrm{CuO}$ matrix in the visible range, with a progressive increase of transmittance for higher wavelengths, which is a feature that is in agreement with the literature [46].

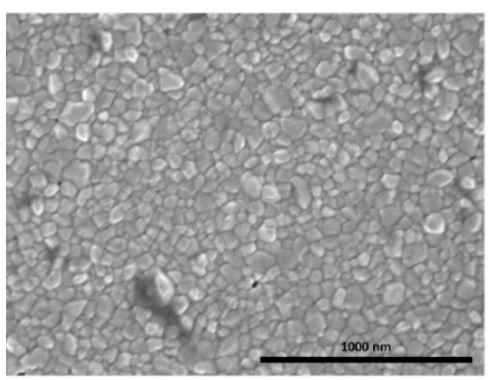

(a)

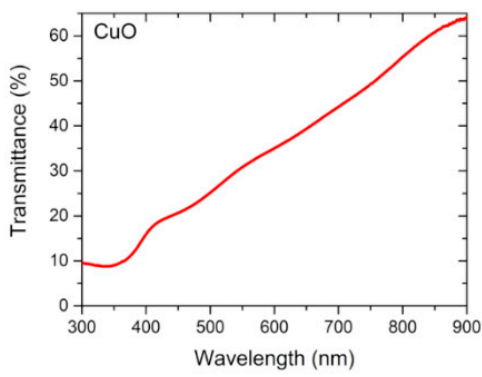

(b)

Figure 3. Top-view SEM micrograph of the $\mathrm{CuO}$ matrix annealed at $700{ }^{\circ} \mathrm{C}(\mathbf{a})$ and the respective optical transmittance spectrum (b).

The microstructural analysis of the annealed plasmonic thin films revealed the presence of noble nanoparticles (bright spots) in the different nanocomposite thin films ((a) and (b) in Figures 4-6), which suggests that the growth of nanoparticles might be facilitated by easier diffusion of Au and Ag atoms through grain boundaries of the $\mathrm{CuO}$ matrix. The $\mathrm{Au}: \mathrm{CuO}$ (Figure 4) film is the one that presents the highest nanoparticles' density at the surface $\left(127 \mu \mathrm{m}^{-2}\right)$ with an average size of about $33 \mathrm{~nm}$ (Figure $4 \mathrm{c}$ ). Moreover, the Au nanoparticles are relatively close to each other (Figure 4d) and they are presumably spherical since their aspect ratio distribution is narrow and close to 1, as seen in Figure 4e.

(a)

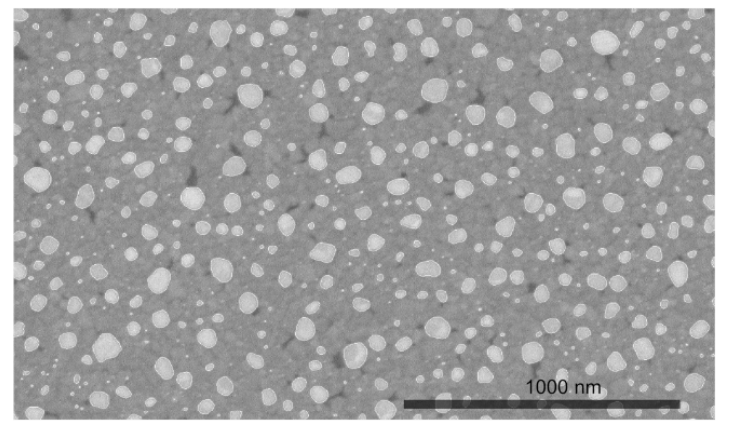

(c)
Backscattered electrons

(d) (b) Thresholded image

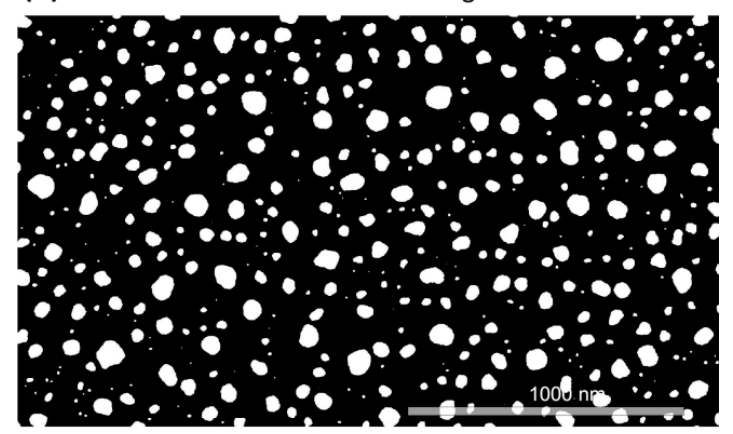

(e)
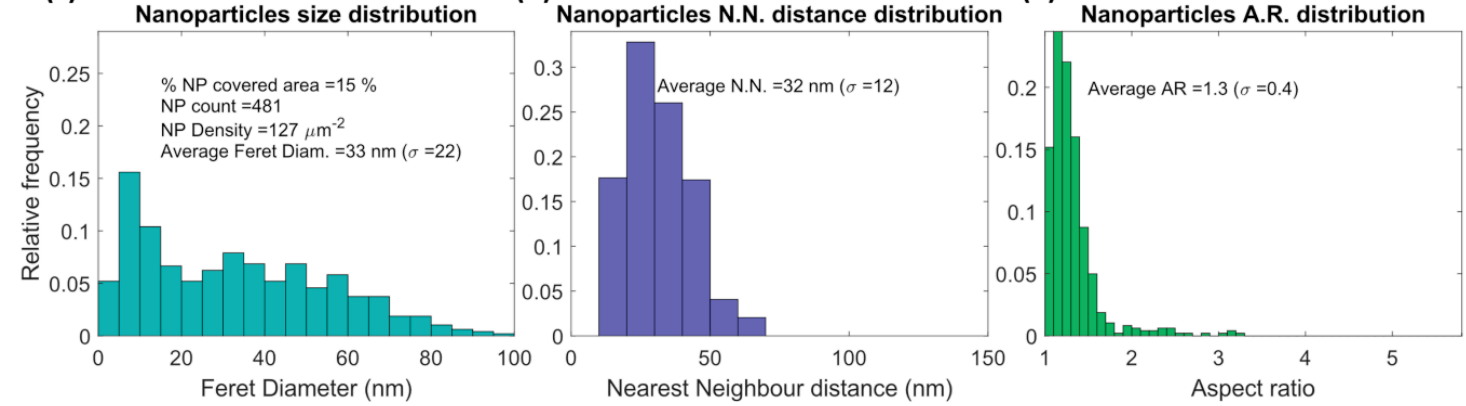

Figure 4. Au nanoparticle distribution analysis, using a MATLAB algorithm: (a) top-view SEM micrograph with atomic weight contrast and (b) processed and threshold micrograph showing the exposed Au nanoparticles, with 15\% Au coverage area. Distribution histograms are displayed in (c) for the nanoparticles Feret diameter, (d) for the nearest neighbor distance, and (e) for the aspect ratio. 
Regarding the $\mathrm{Ag}: \mathrm{CuO}$ film (Figure 5), the average size of Ag nanoparticles was estimated to be $15 \mathrm{~nm}$. However, the nanoparticles' density at the surface $\left(69 \mu \mathrm{m}^{2}\right)$ is much smaller than in the other films (Figure 5c), which leads to the highest distance between the nanoparticles (Figure 5d). In fact, the formation of islands of $\mathrm{Ag}$ (micro-sized agglomerates with parallelepiped shape) was observed on the surface of the film (not shown here) [28]. This explains the low amount of nanosized Ag particles, which is a behavior that was not expected when taking into account the relatively high Ag atomic concentration determined for the as-deposited film.

The Au-Ag:CuO film (Figure 6) presents values between those belonging to the monometallic counterparts (Figures 4 and 5). It presents a density of Au-Ag nanoparticles at the surface of $100 \mu^{-2}$, with an average size estimated to be $30 \mathrm{~nm}$ (Figure 6c). Moreover, the nearest neighbor distance distribution is broader than in the Au film and narrower than in the Ag film. Moreover, this system shows the widest aspect ratio distribution, with an average value of 1.5 , which proves that both spherical and irregular nanoparticles are present in the film's surface.

The different microstructures achieved by the films with the thermal treatment originated different optical transmittance responses, as shown in Figure 7. The high Au nanoparticles' density at the surface and their quasi-spherical shape, observed in the $\mathrm{Au}: \mathrm{CuO}$ film (Figure 4), gave rise to a well-defined and sharp transmittance LSPR (T-LSPR) band at $719 \mathrm{~nm}$ (Figure $7 \mathrm{a}$ ), with a high transmittance amplitude, at about 15 percentage points (i.e., the difference between the maximum and the minimum band's peak).

On the other hand, a T-LSPR band was also observed for the Ag:CuO film (Figure 7b), appearing at shorter wavelengths $(\sim 393 \mathrm{~nm})$ as is typical of the Ag nanoparticles [3,28]. However, despite the narrow shape, due to its slightly larger nanoparticle aspect ratio distribution, the LSPR band is also less intense since the number of Ag nanoparticles at the surface is scarce, which presents only a transmittance amplitude of $\sim 10$ percentage points.

(a)

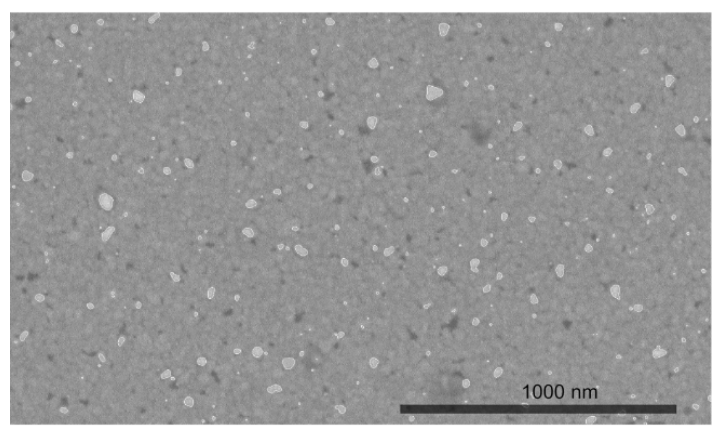

(c)
Backscattered electrons

(d)

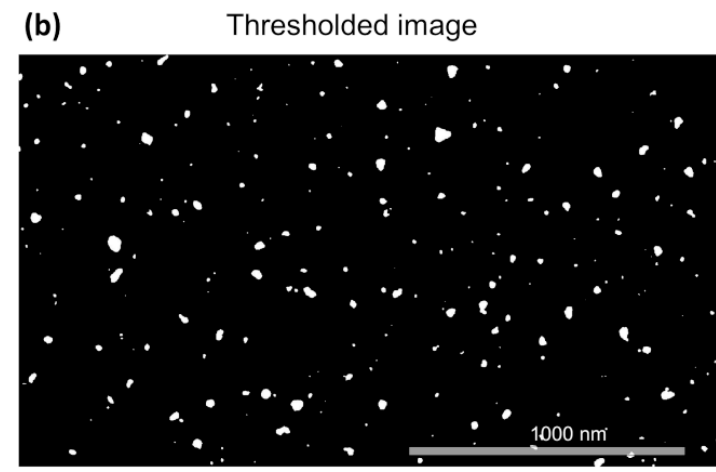

(e)
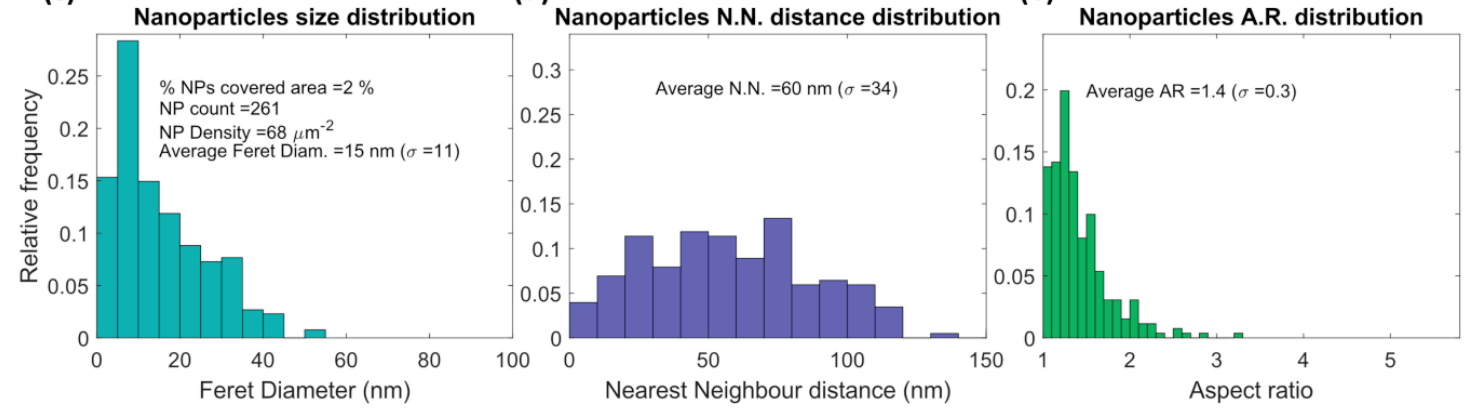

Figure 5. Ag nanoparticle distribution analysis, using a MATLAB algorithm: (a) top-view SEM micrograph with atomic weight contrast and (b) processed and threshold micrograph showing the exposed Ag nanoparticles, with 2\% Ag coverage area. Distribution histograms are displayed in (c) for nanoparticles Feret diameter, (d) for the nearest neighbor distance, and (e) for the aspect ratio. 
(a)

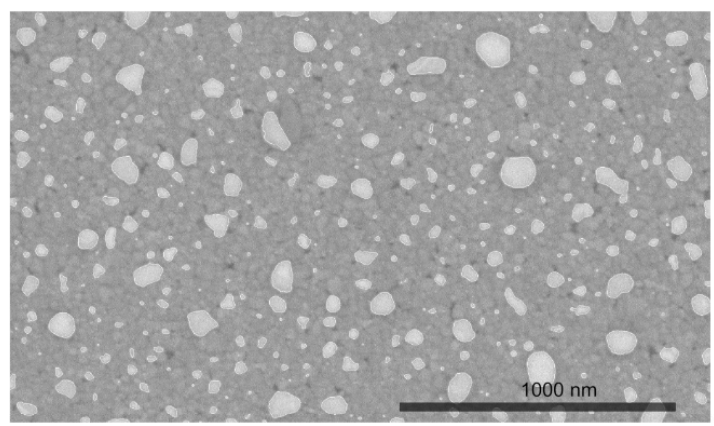

(c)

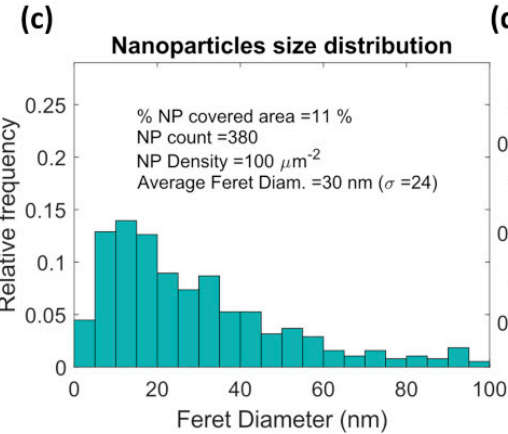

(d)

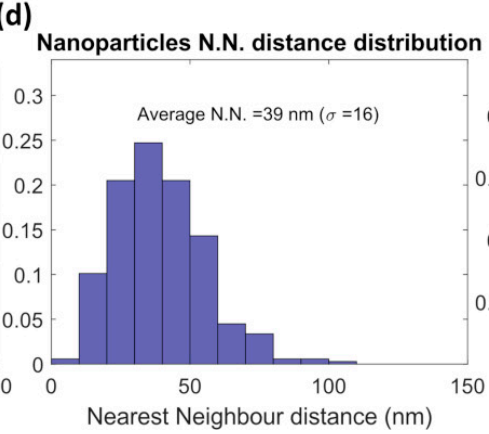

Thresholded image

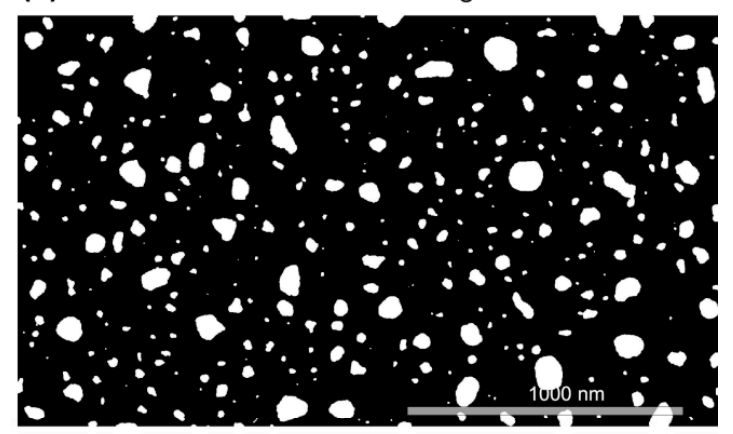

(e)

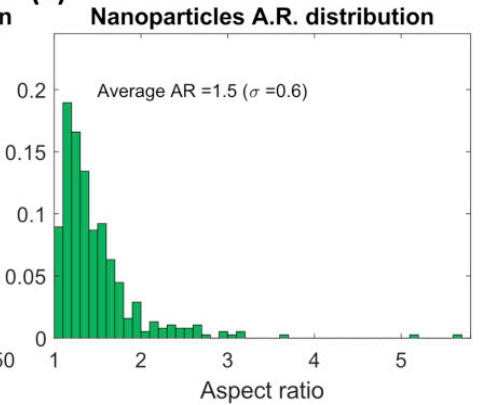

Figure 6. Au-Ag nanoparticle distribution analysis, using a MATLAB algorithm: (a) top-view SEM micrograph with atomic weight contrast and $(\mathbf{b})$ processed and threshold micrograph showing the exposed Au-Ag nanoparticles, with 11\% Au-Ag coverage area. Distribution histograms are displayed in (c) for nanoparticles Feret diameter, (d) for the nearest neighbor distance, and (e) for the aspect ratio.

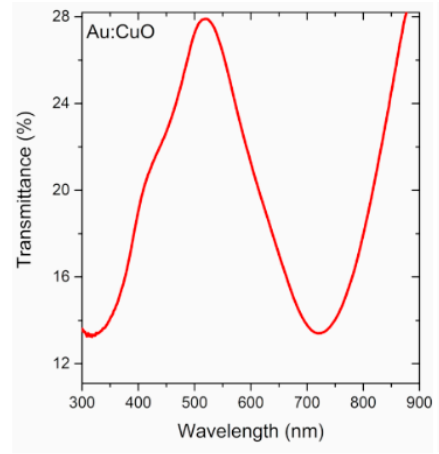

(a)

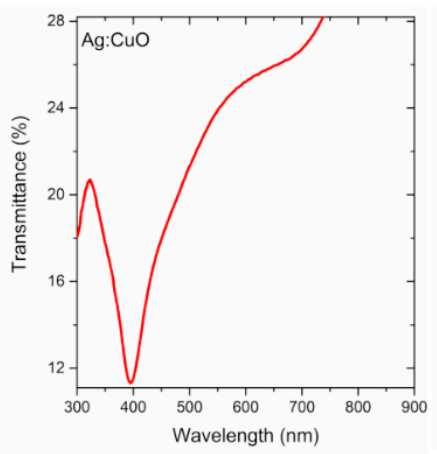

(b)

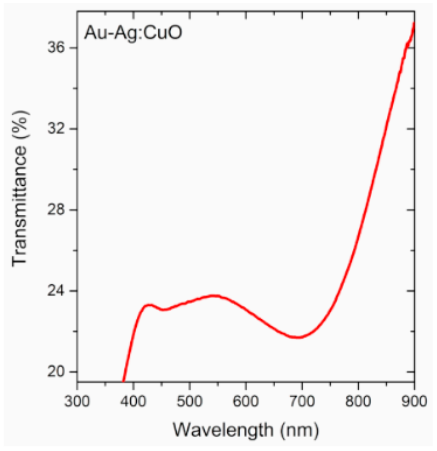

(c)

Figure 7. Transmittance spectra of the $\mathrm{Au}: \mathrm{CuO}(\mathbf{a}), \mathrm{Ag}: \mathrm{CuO}(\mathbf{b})$, and $\mathrm{Au}-\mathrm{Ag}: \mathrm{CuO}(\mathbf{c})$ thin films after in-air annealing.

Concerning the Au-Ag:CuO film, two shifted LSPR peaks are observed ( 450 and $676 \mathrm{~nm})$, even though the second one is much more pronounced (Figure 7c). The presence of two peaks might suggest the presence of separate phases of Ag and Au nanoparticles in these films, but since they are shifted from their initial positions, the formation of an alloy of Au-Ag bimetallic nanoparticles cannot be disregarded. Furthermore, as observed in Figure 6, the film presents both spherical and elongated nanoparticles, which contribute to the LSPR band widening and, therefore, appears much less intense.

\subsection{Sensitivity Tests Using Exposure to $\mathrm{O}_{2}$}

In order to test the films' sensitivity to refractive index changes promoted by the presence and/or adsorption of gas molecules, they were exposed to a test gas $\left(\mathrm{O}_{2}\right)$. Figure 8 presents the LSPR peak position (transmittance) of the three systems, during five cycles under vacuum, and $\mathrm{O}_{2}$ at atmospheric pressure. As expected from this type of sensor, the transmittance shift due to a change in the refractive 
index is typically very short, in the order of tenths of percentage points [2,47]. Anyway, it is possible to observe that the films responded consistently to the presence of the gas. The T-LSPR peak shifted to lower transmittances when the $\mathrm{O}_{2}$ was introduced, which decreases by $0.35,0.11$, and 0.43 percentage points for the $\mathrm{Au}, \mathrm{Ag}$, and $\mathrm{Au}-\mathrm{Ag}: \mathrm{CuO}$ films, respectively. These results are consistent with what has been already published for $\mathrm{Au}_{-} \mathrm{TiO}_{2}$ films, but with slightly higher sensitivities [2]. The $\mathrm{Ag}: \mathrm{CuO}$ sample presents the lowest shift and, subsequently, the lowest signal-to-noise ratio $(\sim 3)$. This is believed to result from the morphology achieved after the annealing process (Figure 5), where the presence of Ag nanoparticles at the film's surface is scarce, which might hinder the film's sensitivity. Moreover, the presence of $\mathrm{Au}$ in the $\mathrm{Au}: \mathrm{CuO}$ film and both $\mathrm{Ag}$ and $\mathrm{Au}$ nanoparticles in $\mathrm{Au}-\mathrm{Ag}: \mathrm{CuO}$ film seems to improve the film's response since a higher transmittance shift is observed when the test gas is introduced. In addition to show the highest transmittance shift, the $\mathrm{Au}-\mathrm{Ag}: \mathrm{CuO}$ film also presents the best signal-to-noise ratio ( 123) even though the $\mathrm{Au}: \mathrm{CuO}$ film has also a reasonable value of $\sim 59$. Furthermore, the peak shifts are reproducible every cycle when the test gas is introduced, which suggests that the eventual gas adsorption is reversible.

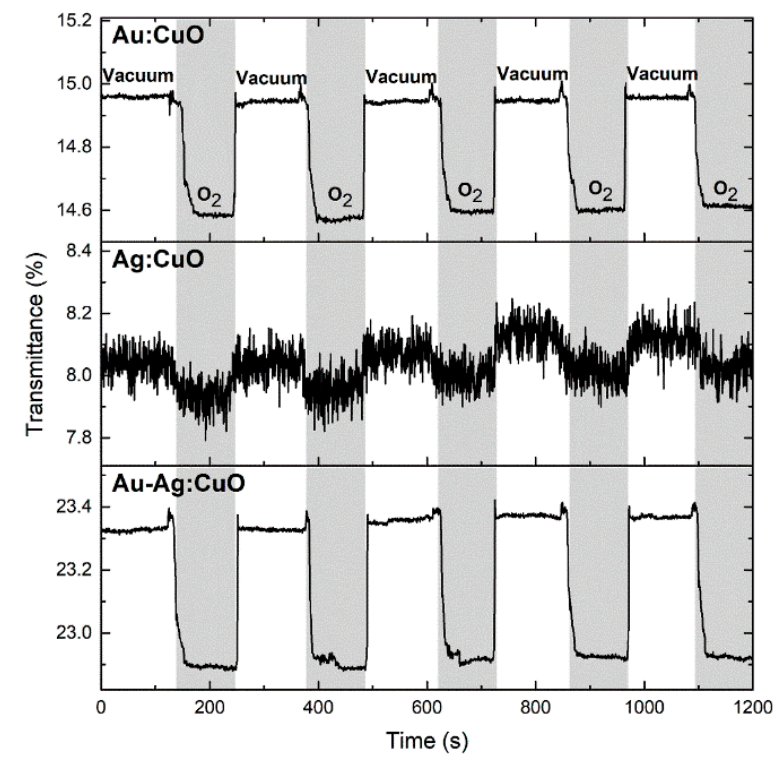

Figure 8. Variation of the LSPR peak position (transmittance minimum) of the $\mathrm{Au}: \mathrm{CuO}, \mathrm{Ag}: \mathrm{CuO}$, and $\mathrm{Au}-\mathrm{Ag}: \mathrm{CuO}$ films over time for five cycles of vacuum and $\mathrm{O}_{2}$ atmosphere.

\section{Conclusions}

$\mathrm{Au}: \mathrm{CuO}, \mathrm{Ag}: \mathrm{CuO}$, and $\mathrm{Au}-\mathrm{Ag}: \mathrm{CuO}$ thin films with nanoplasmonic properties were produced in this work. The films were first deposited by magnetron sputtering for $1 \mathrm{~min}$, using a $\mathrm{Cu}$ target with small metallic pellets $\left(960 \mathrm{~mm}^{2}\right.$ pellet area) and a target potential limited to $500 \mathrm{~V}$. Then, the different films were annealed up to $700^{\circ} \mathrm{C}$ in order to promote the nanoparticles' growth and structural changes.

The composition analysis revealed the presence of reasonable amounts of noble metals in a $\mathrm{CuO}$ matrix, which becomes stoichiometric after a thermal treatment in air. Furthermore, the annealing induced structural and morphological changes that influenced the LSPR responses of the thin films. Due to the presence of spherical Au nanoparticles with high density at the surface, the $\mathrm{Au}: \mathrm{CuO}$ film presented the most well-defined and pronounced transmittance LSPR band at $\sim 719 \mathrm{~nm}$, while the Ag:CuO film showed a narrower but less intense band at shorter wavelengths ( $\sim 393 \mathrm{~nm})$ due to the scarce number of Ag nanoparticles at the surface. However, despite the fact that the $\mathrm{Au}-\mathrm{Ag}: \mathrm{CuO}$ film has two T-LSPR peaks ( 450 and $676 \mathrm{~nm}$ ) with relatively low intensity, it showed to be the most sensitive to the refractive index changes, such as to the $\mathrm{O}_{2}$ gas presence, followed after by $\mathrm{Au}: \mathrm{CuO}$ and Ag:CuO films. 
In conclusion, this work proves that the sensitivity of $\mathrm{Au}-\mathrm{Ag}: \mathrm{CuO}$ thin films to the test gas $\left(\mathrm{O}_{2}\right)$ can be improved by preparing bimetallic noble nanoparticles embedded in the $\mathrm{CuO}$ matrix. Hence, this configuration might be preferable to use for LSPR gas sensing.

Author Contributions: Conceptualization, J.B., F.V.; methodology, M.S.R., J.B.; software, M.S.R.; validation, M.P., M.S.R., J.B., F.V.; formal analysis, M.P., M.S.R., J.B., F.V.; investigation, M.P., M.S.R., J.B.; resources, J.B., F.V.; data curation, J.B., M.S.R., F.V.; writing-original Draft preparation, M.P., J.B.; writing-review and Editing, J.B., F.V.; visualization, M.P., M.S.R., J.B., F.V.; supervision, J.B., F.V.; project administration, F.V.; funding acquisition, J.B., F.V.

Funding: This research was funded by the Portuguese Foundation for Science and Technology (FCT) in the framework of the Strategic Funding UID/FIS/04650/2019; and by the projects NANOSENSING POCI-01-0145-FEDER-016902, with FCT reference PTDC/FIS-NAN/1154/2014; and project NANO4BIO POCI-01-0145-FEDER-032299, with FCT reference PTDC/FIS-MAC/32299/2017 supported this work. Manuela Proença acknowledges her PhD Scholarship from FCT, with reference SFRH/BD/137076/2018. Joel Borges acknowledges FCT for his Researcher Contract from project NANO4BIO, CTTI-149/18-CF(1). Marco S. Rodrigues acknowledges FCT for his PhD Scholarship, SFRH/BD/118684/2016.

Conflicts of Interest: The authors declare no conflict of interest.

\section{References}

1. Proença, M.; Borges, J.; Rodrigues, M.S.; Domingues, R.P.; Dias, J.P.; Trigueiro, J.; Bundaleski, N.; Teodoro, O.M.N.D.; Vaz, F. Development of $\mathrm{Au} / \mathrm{CuO}$ nanoplasmonic thin films for sensing applications. Surf. Coat. Technol. 2018, 343, 178-185. [CrossRef]

2. Rodrigues, M.S.; Borges, J.; Proença, M.; Pedrosa, P.; Martin, N.; Romanyuk, K.; Kholkin, A.L.; Vaz, F. Nanoplasmonic response of porous $\mathrm{Au}-\mathrm{TiO}_{2}$ thin films prepared by oblique angle deposition. Nanotechnology 2019, 30, 22. [CrossRef]

3. Borges, J.; Ferreira, C.G.; Fernandes, J.P.C.; Rodrigues, M.S.; Proença, M.; Apreutesei, M.; Alves, E.; Barradas, N.P.; Moura, C.; Vaz, F. Thin films of Ag-Au nanoparticles dispersed in $\mathrm{TiO}_{2}$ : Influence of composition and microstructure on the LSPR and SERS responses. J. Phys. D. Appl. Phys. 2018, 51, 205102. [CrossRef]

4. Borges, J.; Kubart, T.; Kumar, S.; Leifer, K.; Rodrigues, M.S.; Duarte, N.; Martins, B.; Dias, J.P.; Cavaleiro, A.; Vaz, F. Microstructural evolution of $\mathrm{Au} / \mathrm{TiO}_{2}$ nanocomposite films: The influence of Au concentration and thermal annealing. Thin Solid Films 2015, 580, 77-88. [CrossRef]

5. $\quad$ Borges, J.; Pereira, R.M.S.; Rodrigues, M.S.; Kubart, T.; Kumar, S.; Leifer, K.; Cavaleiro, A.; Polcar, T.; Vasilevskiy, M.I.; Vaz, F. Broadband optical absorption caused by the plasmonic response of coalesced Au nanoparticles embedded in a $\mathrm{TiO}_{2}$ matrix. J. Phys. Chem. C 2016, 120, 16931-16945. [CrossRef]

6. Ghosh, S.K.; Pal, T. Interparticle coupling effect on the surface plasmon resonance of gold nanoparticles: From theory to applications. Chem. Rev. 2007, 107, 4797-4862. [CrossRef]

7. Hutter, E.; Fendler, J.H. Exploitation of localized surface plasmon resonance. Adv. Mater. 2004, 16, 1685-1706. [CrossRef]

8. Toudert, J.; Simonot, L.; Camelio, S.; Babonneau, D. Advanced optical effective medium modeling for a single layer of polydisperse ellipsoidal nanoparticles embedded in a homogeneous dielectric medium: Surface plasmon resonances. Phys. Rev. B 2012, 86, 045415. [CrossRef]

9. Politano, A.; Formoso, V.; Chiarello, G. Dispersion and damping of gold surface plasmon. Plasmonics 2008, 3, 165-170. [CrossRef]

10. Pitarke, J.M.; Silkin, V.M.; Chulkov, E.V.; Echenique, P.M. Theory of surface plasmons and surface-plasmon polaritons. Rep. Prog. Phys. 2007, 70, 1. [CrossRef]

11. Scholl, J.A.; Koh, A.L.; Dionne, J.A. Quantum plasmon resonances of individual metallic nanoparticles. Nature 2012, 483, 421-427. [CrossRef]

12. Goyenola, C.; Gueorguiev, G.K.; Stafström, S.; Hultman, L. Fullerene-like CS $x$ : A first-principles study of synthetic growth. Chem. Phys. Lett. 2011, 506, 86-91. [CrossRef]

13. Rodrigues, M.S.; Borges, J.; Gabor, C.; Munteanu, D.; Apreutesei, M.; Steyer, P.; Lopes, C.; Pedrosa, P.; Alves, E.; Barradas, N.P.; et al. Functional behaviour of $\mathrm{TiO}_{2}$ films doped with noble metals. Surf. Eng. 2016, 32, 554-561. [CrossRef] 
14. Torrell, M.; Cunha, L.; Cavaleiro, A.; Alves, E.; Barradas, N.P.; Vaz, F. Functional and optical properties of $\mathrm{Au}: \mathrm{TiO}_{2}$ nanocomposite films: The influence of thermal annealing. Appl. Surf. Sci. 2010, 256, 6536-6542. [CrossRef]

15. Zhao, Y.; Yang, Y.; Cui, L.; Zheng, F.; Song, Q. Electroactive Au@Ag nanoparticles driven electrochemical sensor for endogenous $\mathrm{H}_{2} \mathrm{~S}$ detection. Biosens. Bioelectron. 2018, 117, 53-59. [CrossRef] [PubMed]

16. Ghodselahi, T.; Arsalani, S.; Neishaboorynejad, T. Synthesis and biosensor application of Ag@Au bimetallic nanoparticles based on localized surface plasmon resonance. Appl. Surf. Sci. 2014, 301, 230-234. [CrossRef]

17. Borges, J.; Buljan, M.; Sancho-Parramon, J.; Bogdanovic-Radovic, I.; Siketic, Z.; Scherer, T.; Kübel, C.; Bernstorff, S.; Cavaleiro, A.; Vaz, F.; et al. Evolution of the surface plasmon resonance of Au:TiO 2 nanocomposite thin films with annealing temperature. J. Nanopart. Res. 2014, 16, 2790. [CrossRef]

18. Petryayeva, E.; Krull, U.J. Localized surface plasmon resonance: Nanostructures, bioassays and biosensing-A review. Anal. Chim. Acta 2011, 706, 8-24. [CrossRef] [PubMed]

19. Cesca, T.; Michieli, N.; Kalinic, B.; Balasa, I.G.; Rangel-Rojo, R.; Reyes-Esqueda, J.A.; Mattei, G. Bidimensional ordered plasmonic nanoarrays for nonlinear optics, nanophotonics and biosensing applications. Mater. Sci. Semicond. Process. 2019, 92, 2-9. [CrossRef]

20. Dwivedi, C.; Chaudhary, A.; Srinivasan, S.; Nandi, C.K. Polymer stabilized bimetallic alloy nanoparticles: Synthesis and catalytic application. Colloid Interface Sci. Commun. 2018, 24, 62-67. [CrossRef]

21. Khlebtsov, B.N.; Liu, Z.; Ye, J.; Khlebtsov, N.G. Au@Ag core/shell cuboids and dumbbells: Optical properties and SERS response. J. Quant. Spectrosc. Radiat. Transf. 2015, 167, 64-75. [CrossRef]

22. Sangpour, P.; Akhavan, O.; Moshfegh, A.Z. The effect of Au/Ag ratios on surface composition and optical properties of co-sputtered alloy nanoparticles in Au-Ag: $\mathrm{SiO}_{2}$ thin films. J. Alloy. Compd. 2009, 486, $22-28$. [CrossRef]

23. Sangpour, P.; Akhavan, O.; Moshfegh, A.Z. rf reactive co-sputtered Au-Ag alloy nanoparticles in $\mathrm{SiO}_{2}$ thin films. Appl. Surf. Sci. 2007, 253, 7438-7442. [CrossRef]

24. Hareesh, K.; Joshi, R.P.; Sunitha, D.V.; Bhoraskar, V.N.; Dhole, S.D. Anchoring of Ag-Au alloy nanoparticles on reduced graphene oxide sheets for the reduction of 4-nitrophenol. Appl. Surf. Sci. 2016, 389, 1050-1055.

25. Tiunov, I.A.; Gorbachevskyy, M.V.; Kopitsyn, D.S.; Kotelev, M.S.; Ivanov, E.V.; Vinokurov, V.A.; Novikov, A.A. Synthesis of large uniform gold and core-shell gold-silver nanoparticles: Effect of temperature control. Russ. J. Phys. Chem. A 2016, 90, 152-157. [CrossRef]

26. Song, Y.; Liu, K.; Chen, S. AgAu bimetallic janus nanoparticles and their electrocatalytic activity for oxygen reduction in alkaline media. Langmuir 2012, 28, 17143-17152. [CrossRef] [PubMed]

27. Blaber, M.G.; Arnold, M.D.; Harris, N.; Ford, M.J.; Cortie, M.B. Plasmon absorption in nanospheres: A comparison of sodium, potassium, aluminium, silver and gold. Phys. B Condens. Matter 2007, 394, 184-187. [CrossRef]

28. Proença, M.; Borges, J.; Rodrigues, M.S.; Meira, D.I.; Sampaio, P.; Dias, J.P.; Pedrosa, P.; Martin, N.; Bundaleski, N.; Teodoro, O.M.N.D.; et al. Nanocomposite thin films based on Au-Ag nanoparticles embedded in a $\mathrm{CuO}$ matrix for localized surface plasmon resonance sensing. Appl. Surf. Sci. 2019, 484, 152-168. [CrossRef]

29. Honda, M.; Ichikawa, Y.; Rozhin, A.G.; Kulinich, S.A. UV plasmonic device for sensing ethanol and acetone. Appl. Phys. Express 2018, 11, 012001. [CrossRef]

30. Kreno, L.E.; Hupp, J.T.; Van Duyne, R.P. Metal-organic framework thin film for enhanced localized surface Plasmon resonance gas sensing. Anal. Chem. 2010, 82, 8042-8046. [CrossRef]

31. Sagle, L.B.; Ruvuna, L.K.; Ruemmele, J.A.; Van Duyne, R.P. Advances in localized surface plasmon resonance spectroscopy biosensing. Nanomedicine 2011, 6, 1447-1462. [CrossRef] [PubMed]

32. Hammond, J.L.; Bhalla, N.; Rafiee, S.D.; Estrela, P. Localized surface plasmon resonance as a biosensing platform for developing countries. Biosensors 2014, 4, 172-188. [CrossRef] [PubMed]

33. Haes, A.J.; Zou, S.; Schatz, G.C.; Van Duyne, R.P. Nanoscale optical biosensor: Short range distance dependence of the localized surface plasmon resonance of noble metal nanoparticles. J. Phys. Chem. B 2004, 108, 6961-6968. [CrossRef]

34. Bingham, J.M.; Anker, J.N.; Kreno, L.E.; Duyne, R.P. Van gas sensing with high-resolution localized surface plasmon resonance spectroscopy. J. Am. Chem. Soc. 2010, 132, 17358-17359. [CrossRef] 
35. Demirdjian, B.; Bedu, F.; Ranguis, A.; Ozerov, I.; Henry, C.R. Water adsorption by a sensitive calibrated gold plasmonic nanosensor. Langmuir 2018, 34, 5381-5385. [CrossRef]

36. Jeong, H.H.; Mark, A.G.; Alarcón-Correa, M.; Kim, I.; Oswald, P.; Lee, T.C.; Fischer, P. Dispersion and shape engineered plasmonic nanosensors. Nat. Commun. 2016, 7, 11331. [CrossRef] [PubMed]

37. Chen, P.; Liedberg, B. Curvature of the localized surface plasmon resonance peak. Anal. Chem. 2014, 86, 7399-7405. [CrossRef]

38. Kedem, O.; Vaskevich, A.; Rubinstein, I. Critical issues in localized plasmon sensing. J. Phys. Chem. C 2014, 118, 8227-8244. [CrossRef]

39. Jung, L.S.; Campbell, C.T.; Chinowsky, T.M.; Mar, M.N.; Yee, S.S. Quantitative interpretation of the response of surface plasmon resonance sensors to adsorbed films. Langmuir 1998, 14, 5636-5648. [CrossRef]

40. Das, S.; Alford, T.L. Structural and optical properties of Ag-doped copper oxide thin films on polyethylene napthalate substrate prepared by low temperature microwave annealing. J. Appl. Phys. 2013, 113, 244905. [CrossRef]

41. Rydosz, A.; Szkudlarek, A. Gas-sensing performance of M-doped CuO-based thin films working at different temperatures upon exposure to propane. Sensors 2015, 15, 20069-20085. [CrossRef]

42. Pedrosa, P.; Fiedler, P.; Lopes, C.; Alves, E.; Barradas, N.P.; Haueisen, J.; Machado, A.V.; Fonseca, C.; Vaz, F. Ag:TiN-coated polyurethane for dry biopotential electrodes: From polymer plasma interface activation to the first EEG measurements. Plasma Process. Polym. 2016, 13, 341-354. [CrossRef]

43. Barradas, N.P.; Jeynes, C. Advanced physics and algorithms in the IBA DataFurnace. Nucl. Instrum. Methods Phys. Res. Sect. B 2008, 266, 1875-1879. [CrossRef]

44. Liu, Y.; Zhang, J.; Zhang, W.; Liang, W.; Yu, B.; Xue, J. Effects of annealing temperature on the properties of copper films prepared by magnetron sputtering. J. Wuhan Univ. Technol. Mater. Sci. Ed. 2015, 30, 92-96. [CrossRef]

45. Pierson, J.F.; Wiederkehr, D.; Billard, A. Reactive magnetron sputtering of copper, silver, and gold. Thin Solid Films 2005, 478, 196-205. [CrossRef]

46. Figueiredo, V.; Elangovan, E.; Gonçalves, G.; Barquinha, P.; Pereira, L.; Franco, N.; Alves, E.; Martins, R.; Fortunato, E. Effect of post-annealing on the properties of copper oxide thin films obtained from the oxidation of evaporated metallic copper. Appl. Surf. Sci. 2008, 254, 3949-3954. [CrossRef]

47. Borensztein, Y.; Delannoy, L.; Djedidi, A.; Barrera, R.G.; Louis, C. Monitoring of the plasmon resonance of gold nanoparticles in $\mathrm{Au} / \mathrm{TiO}_{2}$ catalyst under oxidative and reducing atmospheres. J. Phys. Chem. C 2010, 114, 9008-9021. [CrossRef] 